\title{
A retrospective study of coagulation parametres in patients of pregnancy induced hypertension
}

\author{
Akash C. Chhabra ${ }^{1}$, Navinkumar R. Patel,", \\ ${ }^{1}$ Consultant Pathologist, Private Pathology Laboratory, Ankleshwar, Gujarat, ${ }^{2}$ Associate Professor, Dept. of Pathology, Gujarat \\ Adani Institute of Medical Science, Bhuj-Kutch, Gujarat, India \\ *Corresponding Author: \\ Email: navin.bhuj123@gmail.com
}

Received: $14^{\text {th }}$ February, 2018

Accepted: $6^{\text {th }}$ March, 2018

\begin{abstract}
Introduction: Human pregnancy also known as gestation, is the time between fertilization of ovum to delivery of a baby. It is approcximately a process of 9 months during which new baby develops inside a womb. Physiologically, pregnancy is a hypercoagulative state. Hypercoagulable state in pregnancy is a naturally occuring preventive response to prevent excess loss of blood during delivery. It is essential to know the range of variations of the coagulation factors during normal pregnancy, if any specific component has to be incriminated as a causative agent for the vascular disorder. Preeclampsia is a serious and life threatening complication in pregnant women. It is a pregnancy specific disorder which rates among one of the major causes of maternal and foetal morbidity and mortality.

Aims and Objectives: To evaluate severity of eclampsia by estimating coagulation profile tests in pregnancy induced hypertensive patients. To compare these biochemical parameters between the test group and control group. To correlate the outcome of pregnancy with these biochemical parameters.

Materials and Methods: This retrospective study includes 120 females of uncomplicated pregnancy of age group 16-35 years as a control group and 120 females of same age group with pregnancy with hypertension (PIH) attending obstetric outdoor patient department (OPD) of the institute in the year of 2015. Blood samples are withdrawn from all participants for biochemical markers of coagulation study that includes total platelet count (PC), prothrombin time (PT) and activated partial thromboplastin time (APTT).

Results: Among total $120 \mathrm{PIH}$ participants, 44 (36.67\%) cases were having mild gestational hypertension, $11(9.17 \%)$ cases were having severe gestational hypertension, 34 (28.33\%) cases were having mild preeclampsia and $31(25.83 \%)$ cases were having severe preeclampsia. The mean value of PT and APTT is found to be high in PIH cases as compared to control group participants.

Conclusion: Parameters like total platelet count (PC), prothrombin time (PT) and activated partial thromboplastin time (APTT) can be used routinely as an early indicator for the assessment of PIH cases and also for detection of its severity. It can also be used to monitor the progression of gestational hypertension to prevent serious complications like preeclampsia and eclampsia. More number of preeclampsia cases are seen in underdeveloped and developing countries due to late diagnosis and inadequate antenatal services.
\end{abstract}

Keywords: Eclampsia, Platelet count, Preeclampsia, Pregnancy, APTT, PT.

\section{Introduction}

How pregnancy incites or aggravates hypertension remains unsolved despite decades of intensive research. Indeed, hypertensive disorders remain among the most significant and also a times unsolved problems in obstetrics. During pregnancy, many types of major and minor adverse complications can occur, but hypertension is one of the most common and major complication of pregnancy and also contributes significant morbidity and mortality to mother and/or baby. Preeclampsia is a serious and life threatening complication in pregnant women. It is a pregnancy specific disorder which rates among one of the major causes of maternal and fetal morbidity and mortality. Hypertension is a sign of an underlying major pathological condition which may be pre-existing before pregnancy or appear for the first time during pregnancy. ${ }^{1}$ Various major hematological changes like quantitative and qualitative platelet abnormalities, alteration in hemoglobin concentration and altered blood indices parameters and hypercoagulable state may be seen. Hyper coagulable state in pregnancy is probably a naturally occurring preventive response to prevent excess loss of blood during delivery. ${ }^{2,3}$ During pregnancy many clotting factors like fibrinogen, thrombin level are also increase, sometimes up to three fold times high. However, the other major anticoagulants like protein Cand ant thrombin III, remain constant where as protein $\mathrm{S}$ decreases. ${ }^{4}$

In general, pregnancy activates coagulation cascade. Preeclampsia is a highly thrombotic and procoagulant state with platelet activation and thrombin and fibrin formation. About $20 \%$ of patients have altered coagulation study profile.

According to the criteria of the International society of the study of hypertension in pregnancy, preeclampsia is defined as the blood pressure $\geq 140 / 90 \mathrm{~mm}$ of $\mathrm{Hg}$ occurring after 20 weeks of gestation with proteinuria $\geq 300 \mathrm{mg}$ / day or urinary protein/creatinine ratio $=30 \mathrm{mg} / \mathrm{mmol}$. 


\section{Aims and Objectives}

1. To evaluate severity of eclamsia by esimating biochemical markers of coagulation profile tests like platelet count, PT and APTT in Pregnancy induced hypertensive patients.

2. To evaluate severity of eclamsia by esimating coagulation profile tests in pregnancy induced hypertensive patients.

3. To compare these biochemical parameters between the test group and control group.

4. To correlate the outcome of pregnancy with these biochemical parameters.

\section{Materials and Methods}

This retro prospective study was conducted in central clinical laboratory of pathology department at Gujarat Adani Institute of Medical Science, BhujKutch, Gujarat, India. In present study we included 120 female participants of uncomplicated normal going pregnancy between age group 16-35 years as a control group and also another 120female participants of same age group having pregnancy induced hypertension attending obstetric OPD of Gynecology Department of the same institute during the year 2015 .

Inclusion Criteria: In this study, control group consist of 120 women with 3 rd trimester of pregnancy with normal blood pressure, without any proteinuria or edema. ( $n=120)$ In this study, the study group consist of another 120 women with 3rd trimester of pregnancy having history of high blood pressure above 140/90 mm of $\mathrm{Hg}$ on at least two occasions six hours apart current pregnancy together with or without proteinuria, edema and convulsions. $(n=120)$

Exclusion Criteria: Any participant having preexisting hypertension, diabetes mellitus, auto immune disorders, any known bleeding disorders, Neoplastic condition, heart diseases and who are taking anticoagulant drugs were excluded from the study.

All participants were very well explained about this study and whole procedure. After taking proper informed consent, under aseptic precaution her venous blood was collected in two different vacuitainer containing Sodium citrate and EDTA as an anticoagulants. All the samples were centrifuged for 15 minutes at $3000 \mathrm{rpm}$ and the plasma was separated. The separated plasma was transferred in a clean and dry labeled test tube and was tested within 2-3 hours of blood collection. Total platelet counts were done in fully automated 3 part hematology cell counter from EDTA blood while PT and APTT were done on semiautomated coagulation analyzer from citrated blood.

$\mathrm{PIH}$ cases were classified into following four categories,

1. Mild Gestational hypertension(Mild GH): BP between 140-180 $\mathrm{mm}$ of $\mathrm{Hg}$ and diastolic BP between $90-110 \mathrm{~mm}$ of $\mathrm{Hg}$

2. Severe gestational hypertension(Severe GH): Systolic BP above $180 \mathrm{~mm}$ of $\mathrm{Hg}$ and diastolic BP between above $110 \mathrm{~mm}$ of $\mathrm{Hg}$

3. Mild preeclampsia: Platelet count between 1.2 to $1.8 \mathrm{lacs} / \mathrm{cumm}$, prothrombin time between 16-17 sec, activated partial thromboplastin time between 32-35 sec.

4. Severe preeclampsia: Platelet count less than 1.2 lacs/cumm, prothrombin time more than $17 \mathrm{sec}$, activated partial thromboplastin time more than 35 sec.

Chi square test and $\mathrm{p}$ value is calculated by using Graph pad Prism software

\section{Results}

In this retrospective study, a total of 240 pregnant female participants were included, out of which 120 were in control group and 120 were in study group of the same age group.

Table 1: Age wise distribution of participants

\begin{tabular}{|c|c|c|}
\hline Age (yr) & $\begin{array}{c}\text { Number of } \\
\text { cases }(\mathbf{n = 1 2 0})\end{array}$ & Percentage \% \\
\hline $16-20$ & 09 & $7.5 \%$ \\
\hline $21-25$ & 45 & $37.5 \%$ \\
\hline $26-30$ & 51 & $42.5 \%$ \\
\hline $31-35$ & 15 & $12.5 \%$ \\
\hline & & 100 \\
\hline Total & 120 & \\
\hline
\end{tabular}

In present study, 51 participants $(42.5 \%)$ were between 26-30 years of age group, which is followed by 45 participants $(37.5 \%)$ were between $21-25$ years of age group.

Table 2: Age wise distribution of various categories of PIH cases

\begin{tabular}{|l|c|c|c|c|}
\hline Age $(\mathbf{y r})$ & Mild GH $(\mathbf{n}=\mathbf{4 4})$ & Severe GH $(\mathbf{n = 1 1})$ & Mild Preeclampsia $(\mathbf{n}=\mathbf{3 4})$ & $\begin{array}{c}\text { Sever Pre eclampsia } \\
(\mathbf{n = 3 1})\end{array}$ \\
\hline $16-20$ & $3(8.18 \%)$ & $1(9.1 \%)$ & $2(5.8 \%)$ & $5(16.13 \%)$ \\
\hline $21-25$ & $25(56.81 \%)$ & $5(45.45 \%)$ & $11(32.35 \%)$ & $10(35.48 \%)$ \\
\hline $26-30$ & $12(27.27 \%)$ & $3(27.27 \%)$ & $19(55.88 \%)$ & $15(48.39 \%)$ \\
\hline $31-35$ & $04(9 \%)$ & $2(18.2 \%)$ & $02(5.8 \%)$ & $03(9.67 \%)$ \\
\hline Total & $44(100 \%)$ & $11(100 \%)$ & $34(100 \%)$ & $31(100 \%)$ \\
\hline
\end{tabular}

Table 2 shows that in present study, 30 participants having gestational hypertension were between 21-25 years of age, and 34 participants were having eclampsia were between 26-30 years of age. 
Table 3: Comparison of biochemical markers of coagulation profile in different categories of PIH

\begin{tabular}{|l|c|c|c|c|c|}
\hline \multicolumn{1}{|c|}{ Parameter } & $\begin{array}{c}\text { Control Group } \\
(\mathbf{n = 1 0 0})\end{array}$ & $\begin{array}{c}\text { Mild GH } \\
(\mathbf{n = 4 4})\end{array}$ & $\begin{array}{c}\text { Moderate GH } \\
(\mathbf{n = 1 1})\end{array}$ & $\begin{array}{c}\text { Mild } \\
\text { Preeclampsia } \\
(\mathbf{n = 3 4})\end{array}$ & $\begin{array}{c}\text { Severe } \\
\text { Preeclampsia } \\
(\mathbf{n = 3 1})\end{array}$ \\
\hline Age (years) & $26.09 \pm 3.4$ & $25.08 \pm 3.4$ & $25.47 \pm 2.50$ & $26.76 \pm 2.9$ & $25.6 \pm 3.82$ \\
\hline $\begin{array}{l}\text { Weeks of } \\
\text { Gestation }\end{array}$ & $35.16 \pm 3.01$ & $36.26 \pm 3.01$ & $35.68 \pm 3.35$ & $36.21 \pm 3.65$ & $35.64 \pm 3.66$ \\
\hline $\begin{array}{l}\text { Platlet count } \\
\text { (lac/mm }\end{array}$ & $3.25 \pm 1.59$ & $2.59 \pm 0.46$ & $2.35 \pm 0.54$ & $1.91 \pm 0.32$ & $1.22 \pm 0.62$ \\
\hline PT (sec) & $13.12 \pm 1.12$ & $14.12 \pm 0.98$ & $15.19 \pm 0.75$ & $16.32 \pm 3.1$ & $17.49 \pm 2.9$ \\
\hline APTT (sec) & $26.58 \pm 1.88$ & $28.12 \pm 1.34$ & $29.12 \pm 1.24$ & $32.56 \pm 4.5$ & $36.14 \pm 7.41$ \\
\hline
\end{tabular}

Mean values of total platelet count, PT and APPT of control group, study group and individual group are shown in table 3 . From this it is clear that, mean values of PT and APTT increases as the severity of PIH increases whereas mean values of total platelet count decreases as the severity of PIH increases. Results of all coagulation parameters are statistically significant ( $<<0.05$ for all parameters).

\section{Discussion}

Preeclampsia is generalised multisystem disease specific to human pregnancy only. ${ }^{5}$ Many hematological abnormalities like low platelet count and decrease in plasma level of some clotting factors may develop in preeclamptic women. ${ }^{6}$ Most dangerous complication of preeclampsia is disseminated intravascular coagulation (DIC) followed by HELLP (hemolysis, elevated hepatic enzyme and low total platelet count) syndrome. Disseminated intravascular coagulation (DIC) is always a secondary obstetrics complication to preeclampsia, eclampsia, abruptio placenta, intrauterine infection, retained dead foetus, hydatidiform mole, prolonged shock, amniotic fluid embolism etc. Thus, coagulation testing must be done in all patients presenting with hypertension to rule out DIC and also HELLP syndrome. So now a days all tests like platelet count and APTT, platelet count and liver function tests, platelet count and lactate dehydrogenase, platelet count and ant thrombin are suggested for early detection and screening of the patients with preeclampsia. $^{7}$

The findings of the present study shows that PIH is more prevalent in first pregnancy and this finding is also consistent with other studies like Leduc et al ${ }^{8}$ $(65 \%)$ and Naaz A et al ${ }^{9}(60 \%)$. Maximum numbers of cases in present study were between 18 to 29 years of age which is also consistent with the studies of Shiv kumarS et al,${ }^{10}$ Prakash J et al, ${ }^{11}$ Priyadarshini Get al, ${ }^{12}$ Nirmala Tet al ${ }^{13}$ and Lakshmi VC et al. ${ }^{14}$

\section{Conclusion}

Various biochemical markers of coagulation study parameters like total platelet count (PC), prothrombin time (PT) and activated partial thromboplastin time
(APTT) can be used routinely as an early indicator for the assessment of PIH cases and also for detection of its severity. It can also be used to monitor the progression of gestational hypertension to prevent serious complications like preeclampsia and eclampsia. More number of preeclampsia cases are seen in underdeveloped and developing countries due to late diagnosis and inadequate antenatal services.

\section{References}

1. Onisai M, Vladareaner AM, Bumbea H, Clorascu M, Pop $\mathrm{C}$, AndreiC, et al. A study of haematological picture and of platelet function in preeclampsia-report of a series of cases. J of Clin Med. 2009;4:326-7.

2. Naaz A, PadugupatiS, Sarma, Sushma P. A Study on Coagulation Profile in Pregnancy Induced Hypertension Cases. IOSR Journal of Biotechnology and Biochemistry. 2015;1(6):82-8.

3. Nirmala T, Kumar Pradeep. Study of Coagulation profile in PIH. Indian Journal of Pathology and Oncology. 2015;2(1):1-6.

4. Metz J, Cincotta R, Francis M, DeRosa L, Balloch A. Screening for consumptive coagulopathy in preeclampsia. Int J Gynaecol Obstet. 1994;46(1):3-9.

5. Steegers EA, von Dadelszen P, Duvekot JJ, Pijnenborg R. Pre-eclampsia. Lancet. 2010;376(9741):631-44.

6. Roberts JM, Redman CW. Pre-eclampsia: more than pregnancy-induced hypertension. Lancet 1993;341:144751.

7. Valensise H, Vasapollo B, Gagliardi G, Novelli GP. Early and late preeclampsia: two different maternal hemodynamic states in the latent phase of the disease. Hypertension. 2008;52(5):873-80.

8. Leduc L, Wheeler JM, Kirshon B, Mitchell P, Cottan DB. Coagulation profile in severe preeclampsia. Obstet Gynecol. 1992;79(1):14-8.

9. Naaz A, Padugupati S, Sarma, SushmaP. A Study on Coagulation Profile in Pregnancy Induced Hypertension Cases. IOSR Journal of Biotechnology and Biochemistry. 2015;1(6):82-8.

10. Sharma SK, Philip J, Whitten CW, Padakandla UB, Landers DF. Assessment of changes in coagulation in parturients using thromboelastography. American society of Anaesthesiologistinc. 1999;90:385-90.

11. Prakash J, Pandey LK, Singh AK, Kar B. Hypertension in pregnancy: Hospital based study. J Assoc Physicians India 2006;54:273.

12. Priyadarshini G, Mohanty RR. Assessment of Coagulation Profile and its Correlation with Severity of Preeclampsia in Women of Odisha. International Journal of Physiology. 2014;3(1):135-40. 
13. Nirmala T, Kumar P. Study of coagulation profile in PIH. Indian Journal of Pathology and Oncology. 2015;2(1):16.

14. Lakshmi CV. Comparative Study of Coagulation Profile in Mild Pre-eclampsia, Severe Pre-eclampsia and Eclampsia. Int J Sci Stud. 2016;4(4):180-3.

How to cite this article: Chhabra CA, Patel NR. A retrospective study of coagulation parametres in patients of pregnancy induced hypertension. Ind J Pathol Oncol, 2018;5(3):411-414. 